Short Communication

\title{
MENOPAUSAL TRANSITION AMONG NORTHERN INDIAN WOMEN
}

\author{
Vijayalakshmi S. ${ }^{1}$, Ramesh Chandrababu ${ }^{2} \&$ Eilean Victoria L. ${ }^{3}$ \\ ${ }^{1}$ Vice Principal, S.B.S College of Nursing, Shohiankalan, Fatehgarh Churian Road, Amristar, Punjab, India. \\ ${ }^{2}$ Assistant Professor, Noor College of Nursing, Bengaluru, Karnataka, India, ${ }^{3}$ Associate Professor, Sri Ramachandra \\ College of Nursing, Sri Ramachandra University, Porur, Chennai, Tamilnadu, India \\ Correspondence: \\ Eilean Victoria L, \\ Mobile : +91 9445103841 E-M ail : eileanl@yahoo.co.in
}

\begin{abstract}
:
According to Indian menopause society research there are about 65 million Indian women over the age of 45 . Average age of menopause in around $48 \mathrm{yrs}$ but it strikes Indian women as young as 30-35 years.

The main aim of the study is to assess the menopausal transition among women residing at selected rural community, Punjab. The study was conducted from July 2012 to December 2012.

The sample from the selected rural community and the research design used for this study was Non experimental design - descriptive survey method. The sample size selected for this study consists of 30 rural women 40-55 years of age from selected rural community at Amritsar. Purposive sampling method was used to select the samples. The tool used in this study was ZEG Berlin menopause rating scale to assess the menopausal transition. The data analysis was done using both descriptive and inferential statistics.

The results reported that more prevalent symptoms were feeling tired $(92.90 \%)$, headache $(88.80 \%)$, joint and muscular discomfort (76.20\%), physical and mental exhaustion (60.09\%), sleeplessness (54.40\%), depressive mood (37.30\%), irritability (36\%), dryness of vagina (36\%), hot flushes and sweating (35.80\%) and anxiety (34.50\%).

The rural women of Amritsar, Punjab experience high prevalence of menopausal symptoms. The high percentage and scores of MRS were observed in perimenopausal and postmenopausal women.
\end{abstract}

Keywords: Menopausal Transition, Rural Community Women, Northern India

\section{Introduction:}

Middle age is one of the turning point in one's life as it brings many changes. It roughly starts in the early forties, when for most of the people it is the best period in their life when their achievement is at the highest point. Midway between the challenges of adulthood and despair of old age, comes the compulsory change menopause in women. Middle age in women includes the gradual winding down of the reproductive system and ending of the child bearing years.

\begin{tabular}{|c|}
\hline Access this article online \\
\hline Quick Response Code \\
\hline
\end{tabular}

Menopause is permanent cessation of menstruation at the end of reproductive life due to loss of ovarian follicular activity. Me nopause is a physiological event in the women life and is caused by aging of ovaries which leads to decline in the production of ovarian gonadotrophins, estrogen and progesterone. The deficiency of these hormones elicits various somatic, vasomotor, sexual and psychological symptoms that impair overall quality of life of women.

Menopause is a difficult process. Women going through the menopause transition may experience a variety of symptoms ranging from vasomotor symptoms to sleep disturbance, mood disorders, loss of sexual desire and vaginal dryness. The symptoms can make it a considerable struggle for those already dealing with their hectic lives. As many as two-third of all women report vasomotor symptoms and over $85 \%$ report at least one menopausal symptom as transition through menopause. The study findings showed that $25 \%$ of women whose symptoms were severe, the resulting discomfort greatly diminish the 
quality of life (RandolphJF, et. al., 2004).

According to Indian menopause society research there are about 65 million Indian women over the age of 45 . Average age of menopause in around 48 yrs but it strikes Indian women as young as 30-35 years. Menopausal health demand is a higher priority in Indian scenario. The goal of INDIAN MENOPAUSE SOCIETY is to enhance awarenesS about menopause and aging through public health and education activities. The year 2011 of Indian menopause society is dedicated to peri and post menopausal women who had been suffering in silence; the theme is "HELPING HER BREEZE THROUGH MENOPAUSE" (Srivastava Saroj, 2011).

Menopause is natural and should not affect a woman's enjoyment of life. Menopause fills many people with unease. But the best way to deal with it is to understand it. $M$ any women have difficulties in coping with the emotional and physical strain of menopause, while others are relatively symptom-free. The study will help to identify menopausal symptoms and plan the future research for educational program.

\section{Materials and methods}

\section{Statement of the problem}

A descriptive study to assess the menopausal transition among women residing at selected rural community at Amritsar, Punjab.

\section{Objectives of the study}

I Assess the menopausal transition among women residing at selected rural community.

I Find out the association between menopausal transition and selected background variables.

\section{? Hypothesis}

Ho1: There is a statistically significant association between menopausal transition and selected background variables.

\section{Methodology:}

The research design used for this study was Non experimental design - descriptive survey method. The sample size selected for this study consists of 30 rural women $40-55$ years of age from selected rural community at Amritsar. Purposive sampling method was used to select the samples. The tool used in this study was background variables and ZEG Berlin menopause rating scale to assess the menopausal transition.

\section{Description of the tool:}

Section-l: It is a structured interview schedule which consists of 2 parts.

I Part-A consists Background variables such as age, marital status, educational status of woman, occupational status of woman, type of family, family socioeconomic status, type of diet and Distance of health care facility from house.

I Part-B consists of Clinical variables such as parity of woman, number of health visits per year, suffering from any menopausal symptoms, suffering from any chronic illness, taking hormone replacement therapy, taking calcium supplements and doing any exercise.

\section{Section - II}

The ZEG Berlin M enopause rating scale (M RS) consists of 11 menopausal symptoms. It includes 5 columns for responses (None, mild, moderate, severe and very severe) with a score of $0,1,2,3$ and 4 respectively. Total score is 44 . For the present study the MRS English version was translated into local language Punjabi.

\begin{tabular}{|l|c|c|}
\hline M enopause symptoms & Score & Percentage \\
\hline No symptoms & 0 & $0 \%$ \\
\hline M ild symptoms & $1-11$ & $1-25 \%$ \\
\hline M oderate symptoms & $12-22$ & $26-50 \%$ \\
\hline Severe symptoms & $23-33$ & $51-75 \%$ \\
\hline Very severe symptoms & $34-44$ & $76-100 \%$ \\
\hline
\end{tabular}

\section{Validity and reliability of the tool:}

The validity of the tool was established in consultation with nursing experts. The reliability was established by testretest method and the Karl Pearson's correlation coefficient formula was used to find the stability and consistency of the tool. It is found to be reliable $(0.81)$ at the 0.01 level.

\section{Method of data collection:}

The study was conducted at chetanpura rural community, 
Amritsar. Written permission was obtained from the medical officer and oral consent was obtained from the subjects after explaining the purpose of the study. The data was collected for a period of 1week from 30 women with 40-55years of age. Descriptive survey was conducted with validated tools. Demographic variables and ZEG Berlin menopause rating scale were used to collect the data for assessing menopausal transition among rural women. Collected data was coded, tabulated and analyzed by descriptive and inferential statistics. Data was put to statistical inferences by using SPSS software package.

\section{Results:}

\section{Background variables:}

Majority of the women were belongs to 46-51years $(43.3 \%)$, married $(80 \%)$, illiterate and having primary education (36.7\%), house wife $(56.7 \%)$ and vegetarian (83.3\%). The data revealed that majority were belongs to joint family (50\%), having 1-3 children (70\%) and monthly family socio economic status upto 30000 and above (43.3\%). Most of them were perimenopausal (43.3\%), suffering from hypertension (33.3\%), not taking HRT(86.7\%), not taking calcium supplements(53.3\%) and not doing any exercise(76.7\%). Total $40 \%$ of women were taking health checkup 5-6 times per year. Distance of health care facility from the house was less than $5 \mathrm{Km}$ for most of the women (40\%). (Table-I)

\section{Menopausal transition:}

Majority of women (66.7\%) are having moderate level of symptoms, $20 \%$ are having severe symptoms and few (13.3\%) are having mild symptoms. The mean value is 17.87 and SD value is \pm 6.279 (Table-II, Fig1).

Table-III revealed that prevalence of menopausal symptoms among women. The findings shows that most severe level of symptoms were sleep problems (26.66\%), bladder problems $(26.66 \%)$, anxiety (23.33\%), irritability $(20 \%)$ and dryness of vagina (20\%). More prevalent moderate level of symptoms were heart discomfort (46.66\%), depressive mood (43.33\%), joint and muscular discomfort $(43.3 \%)$, sexual problems $(40 \%)$, dryness of vagina $(40 \%)$, sleep problems $(36.66 \%)$, irritability (36.66\%), bladder problems (36.66\%), anxiety (30\%) and hot flush and sweating (26.66\%).

\section{Association between variables:}

The data presented in table-IV revealed that significant association was found between menopausal transition and the following background variables such as menopausal status $\left(X^{2}=15.089, P=0.020\right)$, chronic illness status $\left(X^{2}=16.560, P=0.035\right)$ and monthly family socio economic status $\left(X^{2}=12.473, P=0.052\right)$. There is no significant association found between menopausal transition and the following variables such as age, marital status, educational status of woman, occupational status of woman, type of family, type of diet, distance of health care facility from house, parity of woman, number of health visits per year, intake of HRT and calcium supplements and doing exercises.

\section{Discussion :}

The present study revealed that percentages of menopausal symptoms were significantly high in perimenopausal and postmenopausal women. These findings are consistent with the findings of Rahman et al (2010), menopausal symptoms assessment among middle age women in Bangladesh. The results reported that more prevalent symptoms were feeling tired $(92.90 \%)$, headache (88.80\%), joint and muscular discomfort (76.20\%), physical and mental exhaustion (60.09\%), sleeplessness (54.40\%), depressive mood $(37.30 \%)$, irritability $(36 \%)$, dryness of vagina $(36 \%)$, hot flushes and sweating $(35.80 \%)$ and anxiety (34.50\%).

Priya Sharma et al (2011) conducted a study on assessment of knowledge on perimenopause, symptoms experienced and practices of perimenopausal women. The symptoms which were always present were frequent urination $(65.40 \%)$, backpain $(54.80 \%)$, weight gain $(49 \%)$, night sweats $(49.2 \%)$, tiredness (47.1\%), joint pains $(44.20 \%)$, mood swings (41.30\%) irritability $(40.40 \%)$, feel tingling in hands and feet $(40.40 \%)$, difficulty in concentrating (39.40\%), poor memory (36.48\%), difficulty in falling asleep 
(36.48\%), feel depressed (33.60\%) and sudden sensation of heat with flushing (45.12\%).

\section{Conclusion :}

The rural women of Amritsar, Punjab experience high prevalence of menopausal symptoms. The high percentage and scores of MRS were observed in perimenopausal and postmenopausal women. The severity of symptoms were more distressing in perimenopausal and postmenopausal women than premenopausal women.

\section{Acknowledgement:}

The author expresses deep sense of gratitude to Research guide Prof.Dr. Eilean Victoria, M.Sc(N).,PhD., Reader, Sri Ramachandra University, Porur, Chennai for her endless guidance, thoughtful comments, invaluable suggestions and constant encouragement throughout the period of study; appreciate the cooperation of Medical officer, Chetanpura, Amritsar; extend heartfelt thanks to women for their participation; and appreciate the work of Computer Hut staffs. Author likes to acknowledge all those who have helped directly and indirectly to make the fruition of this study possible.

Table-l: Frequency and percentage distribution of background variables of women regarding menopausal transition:

\begin{tabular}{|c|l|c|c|}
\hline S.No & Background variables & Frequency & Percentage $(\%)$ \\
\hline 1 & Age in years & & \\
1.1 & $40-45$ years & 11 & 36.7 \\
1.2 & $46-51$ years & 6 & 43.3 \\
1.3 & $<52$ years & & 20 \\
\hline 2 & Marital status & 1 & 3.3 \\
2.1 & Unmarried & 24 & 80 \\
2.2 & Married & 5 & 16.7 \\
2.3 & Widowed & 0 & 0 \\
2. & Divorced & 11 & 36.7 \\
\hline 3 & Educational status of woman & & 36.7 \\
3.1 & Illiterate & 11 & 3.3 \\
3.2 & Primary education & 1 & 13.3 \\
3.3 & Secondary education & 4 & 10 \\
3.4 & Higher secondary & 3 & \\
3.5 & Graduate and above & 2 & 6.7 \\
\hline 4 & Occupational status of the woman & 6.7 \\
4.1 & Self-employee & 2 & 10 \\
4.2 & Government & 3 & 20 \\
4.3 & Private employee & 6 & 56.7 \\
4.4 & Daily wage labour \\
4.5 & House wife & 17 & \\
\hline
\end{tabular}

\begin{tabular}{|c|c|c|c|}
\hline S.No & Background variables & Frequency & Percentage(\%) \\
\hline 5 & Type of family & & \\
\hline 5.1 & Nuclear family & 12 & 40 \\
\hline 5.2 & Joint family & 15 & 50 \\
\hline 5.3 & Extended family & 3 & 10 \\
\hline 6 & \multicolumn{3}{|c|}{ M onthly family socio economic status (in Rs) } \\
\hline 6.1 & Up to 5000 & 10 & 33.3 \\
\hline 6.2 & Up to 10000 & 5 & 16.7 \\
\hline 6.3 & Up to 15000 & 2 & 6.7 \\
\hline 6.4 & Up to 30000 and above & 13 & 43.3 \\
\hline 7 & Type of diet & & \\
\hline 7.1 & Vegetarian & 25 & 83.3 \\
\hline 7.2 & Non vegetarian & 5 & 16.7 \\
\hline 8 & \multicolumn{3}{|c|}{ Distance of health care facility from house } \\
\hline 8.1 & Less than $5 \mathrm{~km}$ & 12 & 40 \\
\hline 8.2 & $6-10 \mathrm{Km}$ & 6 & 20 \\
\hline 8.3 & $11-15 \mathrm{Km}$ & 7 & 23.3 \\
\hline 8.4 & More than $16 \mathrm{Km}$ & 5 & 16.7 \\
\hline 9 & \multicolumn{2}{|c|}{ Parity of women( number of children) } & \\
\hline 9.1 & Nulliparous & 1 & 3.3 \\
\hline 9.2 & $1-3$ & 21 & 70 \\
\hline 9.3 & $4-6$ & 8 & 26.7 \\
\hline 9.4 & 7 and more & 0 & 0 \\
\hline 10 & \multicolumn{2}{|c|}{ Number of health visits per year } & \\
\hline 10.1 & $1-2$ & 10 & 33.3 \\
\hline 10.2 & $3-4$ & 6 & 20 \\
\hline 10.3 & $5-6$ & 12 & 40 \\
\hline 10.4 & 7 and more & 2 & 6.7 \\
\hline 11 & \multicolumn{2}{|c|}{ Do you experience following symptoms } & \\
\hline 11.1 & $\begin{array}{l}\text { Pre menopause (mood } \\
\text { swings, anxiety, } \\
\text { irritability and nausea) }\end{array}$ & 5 & 16.7 \\
\hline 11.2 & $\begin{array}{l}\text { Perimenopause (Irregular } \\
\text { menses, hot flush, } \\
\text { sweating and pre } \\
\text { menopause symptoms) }\end{array}$ & 13 & 43.3 \\
\hline 11.3 & $\begin{array}{l}\text { Post M enopause (Period } \\
\text { after Complete stoppage } \\
\text { of menstruation for one } \\
\text { complete year) }\end{array}$ & 12 & 40 \\
\hline 12 & \multicolumn{3}{|c|}{ Are you suffering from any chronic illness } \\
\hline 12.1 & Diabetes mellitus & 2 & 6.7 \\
\hline 12.2 & Hypertension & 10 & 33.3 \\
\hline 12.3 & $\begin{array}{l}\text { Diabetes mellitus } \\
\text { and Hypertension }\end{array}$ & 0 & 0 \\
\hline 12.4 & Cardio vascular diseases & 2 & 6.7 \\
\hline 12.5 & Cancer and osteoporosis & 0 & 0 \\
\hline 12.6 & Other illness & 9 & 30 \\
\hline 12.7 & No illness & 7 & 23.3 \\
\hline 13 & \multicolumn{3}{|c|}{ Are you taking hormone replacement therapy } \\
\hline 13.1 & Yes & 4 & 13.3 \\
\hline 13.2 & No & 26 & 86.7 \\
\hline 14 & \multicolumn{2}{|c|}{ Are you taking calcium supplements } & \\
\hline 14.1 & Yes & 14 & 46.7 \\
\hline 14.2 & No & 16 & 53.3 \\
\hline 15 & Are you doing any exercise & & \\
\hline 15.1 & Yes & 7 & 23.3 \\
\hline 15.2 & No & 23 & 76.7 \\
\hline
\end{tabular}


Table-Il: Frequency, percentage, mean, median and standard deviation of women regarding menopausal transition

$(n=30)$

\begin{tabular}{|l|l|c|c|c|c|c|}
\hline S.no & Symptoms level & Frequency & Percentage & Mean & M edian & Standard deviation \\
\hline 1 & Mild symptoms & 4 & $13.3 \%$ & & & \\
\hline 2 & Moderate symptoms & 20 & $66.7 \%$ & 17.87 & 19.00 & \pm 6.279 \\
\hline 3 & Severe symptoms & 6 & $20 \%$ & & & \\
\hline
\end{tabular}

Table-III- Menopause rating scale(MRS)

\begin{tabular}{|l|l|c|c|c|c|c|c|c|c|c|c|}
\hline $\begin{array}{l}\text { Item } \\
\text { No. }\end{array}$ & \multicolumn{2}{|c|}{$\begin{array}{l}\text { Menopausal } \\
\text { Symptoms }\end{array}$} & \multicolumn{2}{c|}{ Mild } & \multicolumn{2}{c|}{ Moderate } & \multicolumn{2}{c|}{ Severe } & \multicolumn{2}{l|}{ Very severe } \\
\hline & & $\mathrm{F}$ & $\%$ & $\mathrm{~F}$ & $\%$ & $\mathrm{~F}$ & $\%$ & $\mathrm{~F}$ & $\%$ & $\mathrm{~F}$ & $\%$ \\
\hline 1 & Hot flush and sweating & 8 & 26.66 & 8 & 26.66 & 8 & 26.66 & 5 & 16.66 & 1 & 3.33 \\
\hline 2 & Heart discomfort & 9 & 30 & 6 & 20 & 14 & 46.66 & 1 & 3.33 & 0 & 0 \\
\hline 3 & Sleep problems & 4 & 13.33 & 6 & 20 & 11 & 36.66 & 8 & 26.66 & 1 & 3.33 \\
\hline 4 & Depressive mood & 1 & 3.33 & 11 & 36.66 & 13 & 43.33 & 3 & 10 & 2 & 6.66 \\
\hline 5 & Irritability & 4 & 13.33 & 7 & 23.33 & 11 & 36.66 & 6 & 20 & 2 & 6.66 \\
\hline 6 & Anxiety & 2 & 6.66 & 11 & 36.66 & 9 & 30 & 7 & 23.33 & 1 & 3.33 \\
\hline 7 & Physical and mental exhaustion & 5 & 16.66 & 13 & 43.33 & 7 & 23.33 & 5 & 16.66 & 0 & 0 \\
\hline 8 & Sexual problems & 4 & 13.33 & 12 & 40 & 12 & 40 & 2 & 6.66 & 0 & 0 \\
9 & Bladder problems & 6 & 20 & 5 & 16.66 & 11 & 36.66 & 8 & 26.66 & 0 & 0 \\
\hline 10 & Dryness of vagina & 7 & 23.33 & 4 & 13.33 & 12 & 40 & 6 & 20 & 1 & 3.33 \\
\hline 11 & Joint and muscular discomfort & 5 & 16.66 & 4 & 13.33 & 13 & 43.33 & 5 & 16.66 & 3 & 10 \\
\hline
\end{tabular}

Table-IV: Association between menopausal transition of women with their selected background variables:

$(n=30)$

\begin{tabular}{|c|c|c|c|c|c|c|c|c|c|}
\hline \multirow[t]{2}{*}{ S.no } & \multirow[t]{2}{*}{ Demographic variables } & \multicolumn{2}{|c|}{ Mild } & \multicolumn{2}{|c|}{ Moderate } & \multicolumn{2}{|c|}{ Severe } & \multirow{2}{*}{$\begin{array}{c}\text { Chi square } \\
\text { value }\end{array}$} & \multirow[t]{2}{*}{$p$-value } \\
\hline & & $\mathrm{F}$ & $\%$ & $\mathrm{~F}$ & $\%$ & $\mathrm{~F}$ & $\%$ & & \\
\hline 1 & Age in years & & & & & & & \multirow{4}{*}{$\begin{array}{c}3.991 \\
\text { NS }\end{array}$} & \multirow[b]{4}{*}{0.407} \\
\hline 1.1 & $40-45$ years & 3 & 27.3 & 7 & 63.6 & 1 & 9.1 & & \\
\hline 1.2 & 46-51 years & 1 & 7.7 & 9 & 69.2 & 3 & 23.1 & & \\
\hline 1.3 & $<52$ years & 0 & 0 & 4 & 66.7 & 2 & 33.3 & & \\
\hline 2 & Marital status & & & & & & & \multirow{5}{*}{$\begin{array}{c}1.571 \\
\text { NS }\end{array}$} & \multirow[b]{5}{*}{0.814} \\
\hline 2.1 & Unmarried & 0 & 0 & 1 & 100 & 0 & 0 & & \\
\hline 2.2 & Married & 4 & 16.7 & 15 & 62.5 & 5 & 20.8 & & \\
\hline 2.3 & Widowed & 0 & 0 & 4 & 80 & 1 & 20 & & \\
\hline 2.4 & Divorced & 0 & 0 & 20 & 66.7 & 6 & 20 & & \\
\hline 3 & Educational status of woman & & & & & & & \multirow{6}{*}{$\begin{array}{c}8.034 \\
\text { NS }\end{array}$} & \multirow{6}{*}{0.430} \\
\hline 3.1 & |lliterate & 2 & 18.2 & 6 & 54.5 & 3 & 27.3 & & \\
\hline 3.2 & Primary education & 1 & 9.1 & 9 & 81.8 & 1 & 9.1 & & \\
\hline 3.3 & Secondary education & 0 & 0 & 0 & 0 & 1 & 100 & & \\
\hline 3.4 & Higher secondary & 1 & 25 & 2 & 50 & 1 & 25 & & \\
\hline 3.5 & Graduate and above & 0 & 0 & 3 & 100 & 0 & 0 & & \\
\hline 4 & \multicolumn{2}{|l|}{ Occupational status of the woman } & & & & & & \multirow{6}{*}{$\begin{array}{c}12.103 \\
\text { NS }\end{array}$} & \multirow{6}{*}{0.147} \\
\hline 4.1 & Self-employee & 0 & 0 & 1 & 50 & 1 & 50 & & \\
\hline 4.2 & Government & 0 & 0 & 2 & 100 & 0 & 0 & & \\
\hline 4.3 & Private employee & 0 & 0 & 1 & 33.3 & 2 & 66.7 & & \\
\hline 4.4 & Daily wage labour & 2 & 33.3 & 2 & 33.3 & 2 & 33.3 & & \\
\hline 4.5 & House wife & 2 & 11.8 & 14 & 82.4 & 1 & 5.9 & & \\
\hline 5 & Type of family & & & & & & & \multirow{4}{*}{$\begin{array}{c}4.017 \\
\text { NS }\end{array}$} & \multirow{4}{*}{0.404} \\
\hline 5.1 & Nuclear family & 1 & 8.3 & 7 & 58.3 & 4 & 33.3 & & \\
\hline 5.2 & Joint family & 3 & 20 & 11 & 73.3 & 1 & 6.7 & & \\
\hline 5.3 & Extended family & 0 & 0 & 2 & 66.7 & 1 & 33.3 & & \\
\hline
\end{tabular}




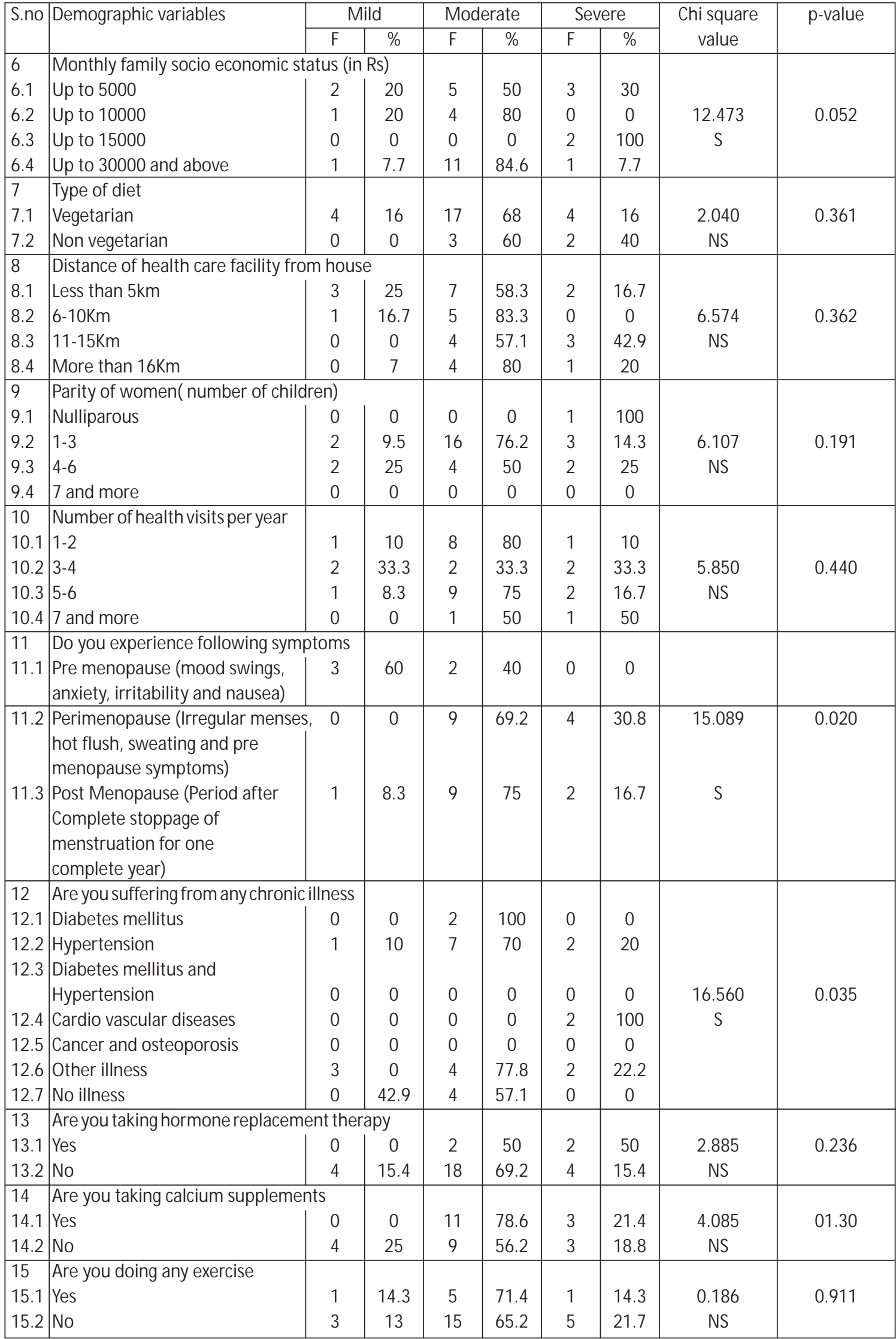




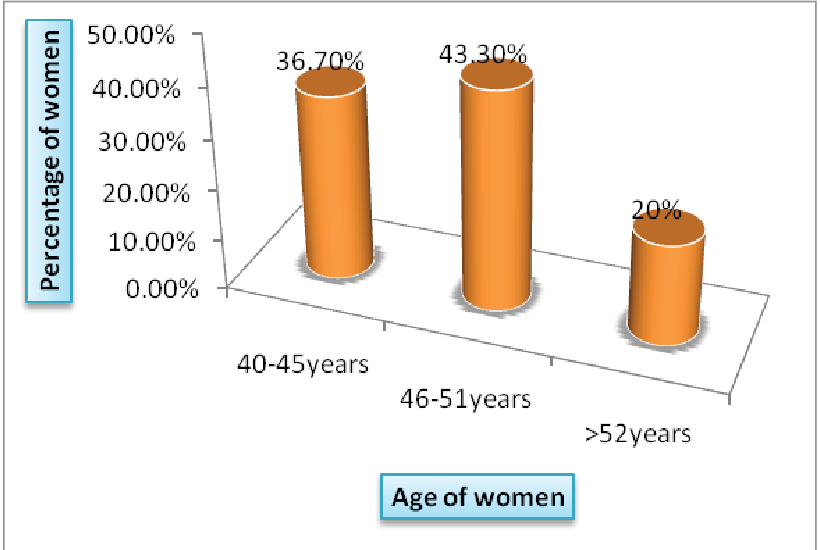

Fig1: Percentage distribution of women according to their age

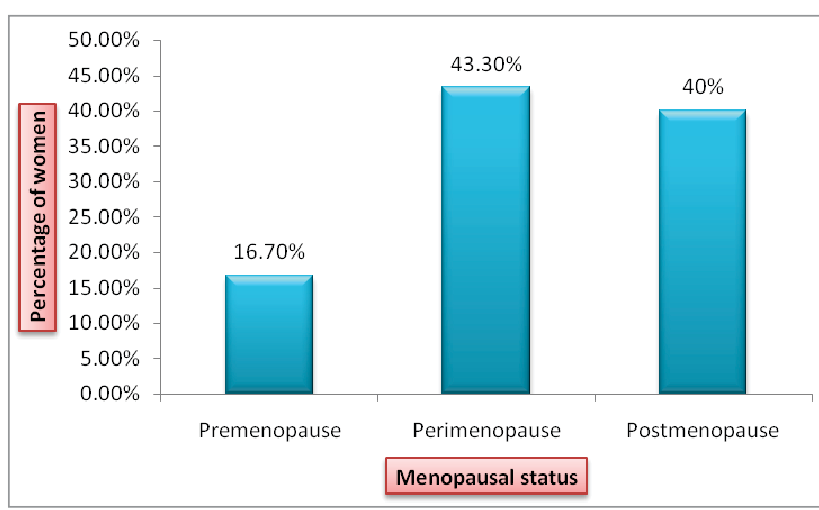

Fig2: Percentage distribution of women according to their menopausal status

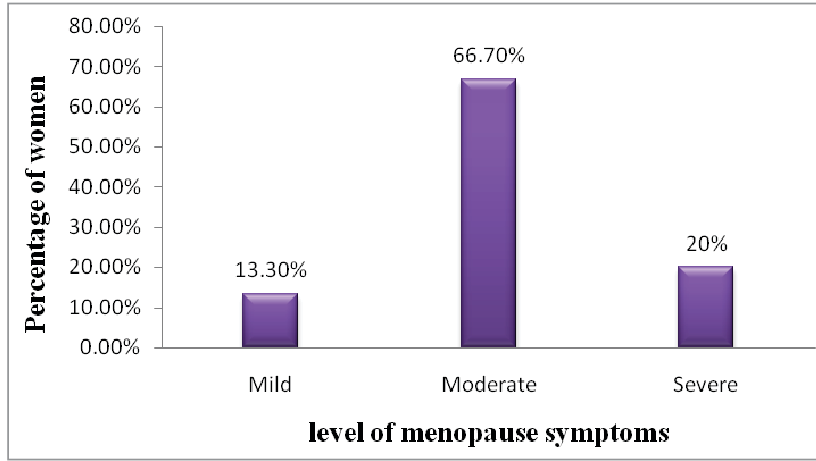

Fig3: Percentage distribution of women regarding level of menopause symptoms

\section{References:}

1. Syamala TS, Sivakami M. Menopause: An emerging issue in India. Economic and political weekly. 2005 Nov 19; 40. (47): 4923.

2. Shahedur R, Faizus $S$ and Asif I. Menopausal symptoms assessment among middle age women in Kushtia, Bangladesh. BMC Research Notes. 2011; 4(188): 1-4. Available from http:// www.biomedcentral. com/1756-0500/4/188.

3. Priya Sharma, Maxie Andrade, Bharathi R Nayak. Assessment of knowledge on perimenopause, symptoms experienced and practices of perimenopausal women. Prism's Nursing Practice. 2012; 7(2-3): 51 62.

4. Kala Bharthi S, Kalavathi S. M enopausal transition. Nightingle nursing times. 2010; 6. (3): 37-38, 41.

5. Sharda Sidhu, Avneet Kaur, Mandeep Sidhu. Age at menopause in educated women of Amritsar. J. Hum. Ecol. 2005; 18. (1): 49-51.

6. Price SL, Storey S, Lake M. M enopause experiences of women in rural areas. J Adv Nurs. 2008; 61. (5): 503-511.

7. Sengupta $A$. The emergence of the menopause in India. Climacteric. 2003; 6: 92-95.

8. Singh A, Arora AK. Profile of menopausal women in rural north India. Climacteric. 2005; 8. (2): 177-184. 